\title{
Accuracy of self-navigated free-breathing isotropic 3D whole heart inversion recovery magnetic resonance for detection of myocardial infarction
}

\author{
Tobias Rutz ${ }^{2^{*}}$, Davide Piccini ${ }^{1}$, Jerome Chaptinel ${ }^{1,3}$, Simone Coppo ${ }^{1,3}$, Gabriella Vincenti ${ }^{2}$, Matthias Stuber ${ }^{3,1}$, \\ Juerg Schwitter ${ }^{2}$
}

From 18th Annual SCMR Scientific Sessions

Nice, France. 4-7 February 2015

\section{Background}

Cardiac magnetic resonance (CMR) allows detection of myocardial scar after myocardial infarction. Usually 2D image planes in short-axis and three long axis orientations are obtained. However to plan in patients with scar e.g. complex electrophysiological intervention for reentry arrhythmias, high-resolution 3D information of the scar is highly desirable. This study therefore evaluates the accuracy of self-navigated isotropic 3D-freebreathing CMR with inversion recovery (3D-SNIR) to detect myocardial scar tissue.

\section{Methods}

Patients after myocardial infarction detected by late gadolinium enhancement on standard 2D inversion recovery sequences (2D LGE) underwent a CMR exam with 3D-SNIR on a 1.5T clinical CMR scanner (Aera, Siemens, Germany). Data acquisition was performed during the most quiescent systolic phase with a prototype segmented 3D radial trajectory with self-navigation after administration of $0.2 \mathrm{mmol} / \mathrm{kg}$ of Gadobutrol. A non-selective IR pulse was added prior to each acquired k-space segment to the segmented, ECG-triggered, fatsaturated radial SSFP imaging sequence. Parameters: TR/TE $3.1 / 1.56 \mathrm{~ms}$, FOV $(220 \mathrm{~mm})^{3}$, matrix $192^{3}$, isotropic voxel size $(1.15 \mathrm{~mm})^{3}$, RF excitation angle $115^{\circ}$, and receiver bandwidth $898 \mathrm{~Hz} / \mathrm{Px}$. TI $(=250-300 \mathrm{~ms})$ was assessed with a $2 \mathrm{D}$ radial scout scan prior to $3 \mathrm{D}$-SNIR.

${ }^{2}$ Division of Cardiology, Cardiac MR Center, University Hospital Lausanne (CHUV), Lausanne, Switzerland

Full list of author information is available at the end of the article
A total of about 12 '000 radial readouts were acquired for each 3D scan during free breathing with 100\% respiratory efficiency. 3D LGE datasets were compared to standard 2D LGE for scar tissue detection with Osirix ${ }^{\circledR}$ software. Short axis $10 \mathrm{~mm}$ slices were reconstructed from 3D LGE datasets by maximum intensity projection to yield a slice thickness of $10 \mathrm{~mm}$. Scar tissue was segmented on reconstructed slices on standard 2D and 3D-SNIR LGE and multiplied by slice thickness.

\section{Results}

Thirteen patients ( 5 females, age $58 \pm 10 \mathrm{y}$ ) were included. Time between 2D LGE and 3D LGE was $59 \pm 64$ days. 3D-SNIR successfully corrected for respiratory motion in all acquisitions. All scars visualized by 2D LGE could be identified by 3D-SNIR (example see figure 1). Bland Altman-analyses and correlations showed a good agreement of quantification of scar volume obtained by 3DSNIR compared to standard 2D LGE: $-6.3 \pm 4.1 \mathrm{ml}$, linear regression: $\mathrm{r}=0.977, \mathrm{p}<0.001$ (figure 2 ). $3 \mathrm{D}$ scar volume was $24.3 \pm 15 \mathrm{ml}$ vs. $2 \mathrm{D} 30.6 \pm 17 \mathrm{ml}, \mathrm{p}<0.001$. Intraobserver variability was $0.3 \pm 4.9 \mathrm{ml}, \mathrm{r}=0.985, \mathrm{p}<0.001$; interobserver $1.5 \pm 9.9 \mathrm{ml}, \mathrm{r}=0.74, \mathrm{p}=0.014$.

\section{Conclusions}

Detection of myocardial scar by 3D-SNIR is feasible and shows a good agreement with standard 2D LGE. The mean difference of $-6.3 \mathrm{ml}$ might be explained by the higher spatial resolution of the 3D sequence. Integration of a phase sensitive inversion recovery pulse warrants testing to further improve 3D quantification of scar. 


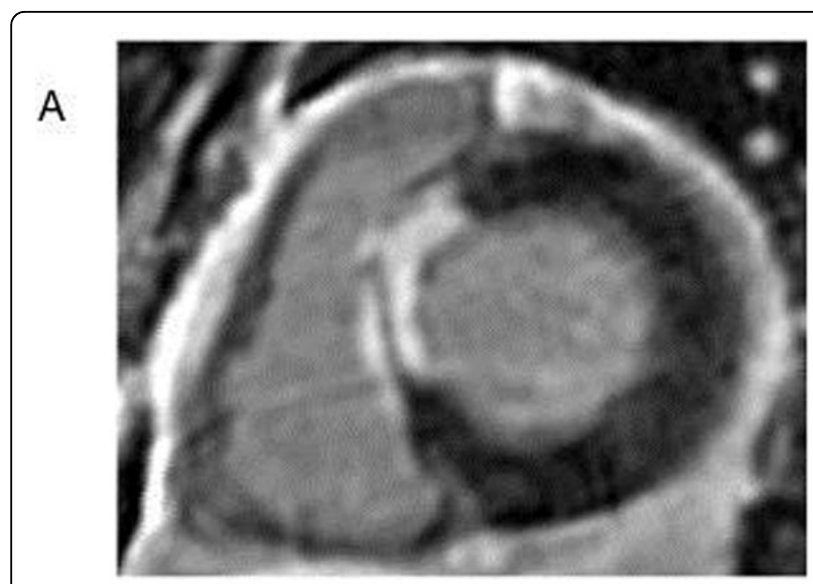

2D late gadolinium enhancement

B

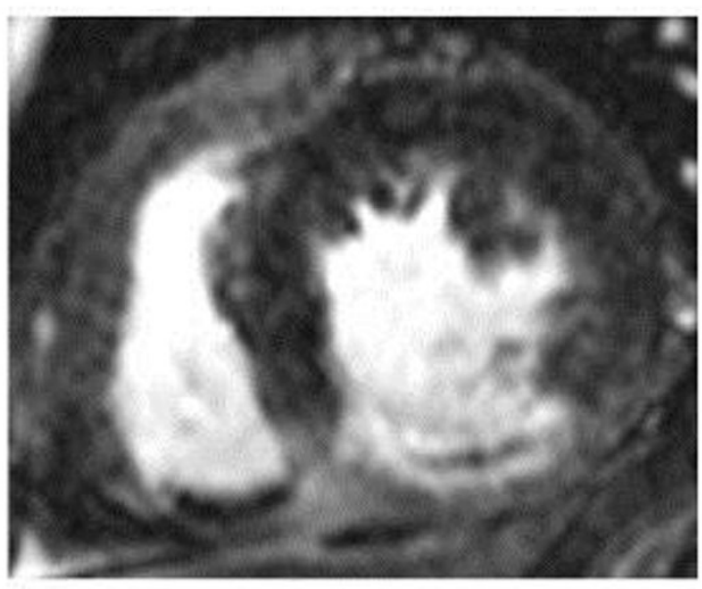

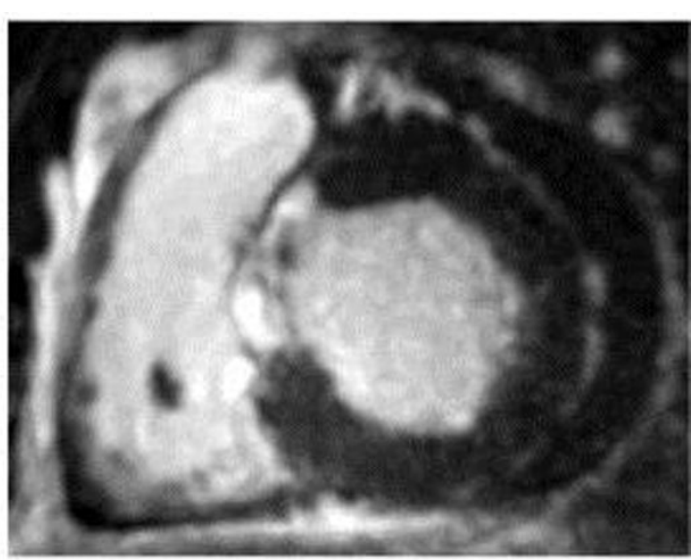

3D late gadolinium enhancement

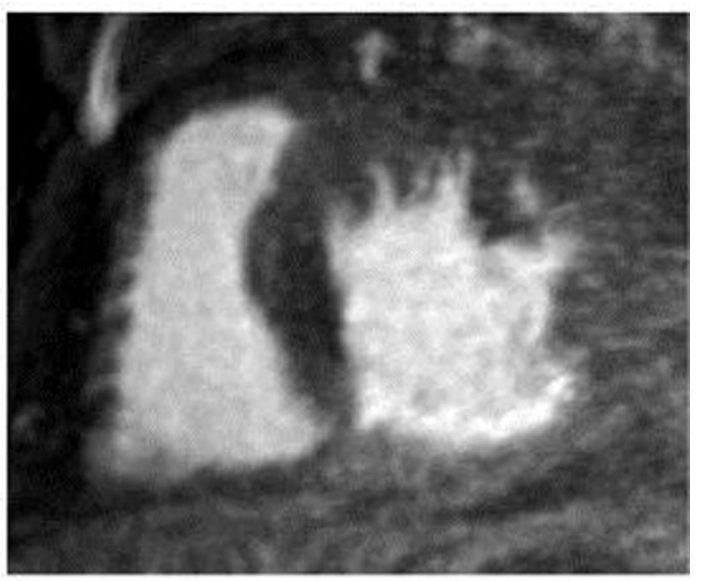

Figure 1 Examples for detection of myocardial scar in the septal (figure 1A) and inferior wall (figure 1B) by 2D (left) and 3D (right) late gadolinium enhancement in 2 patients.

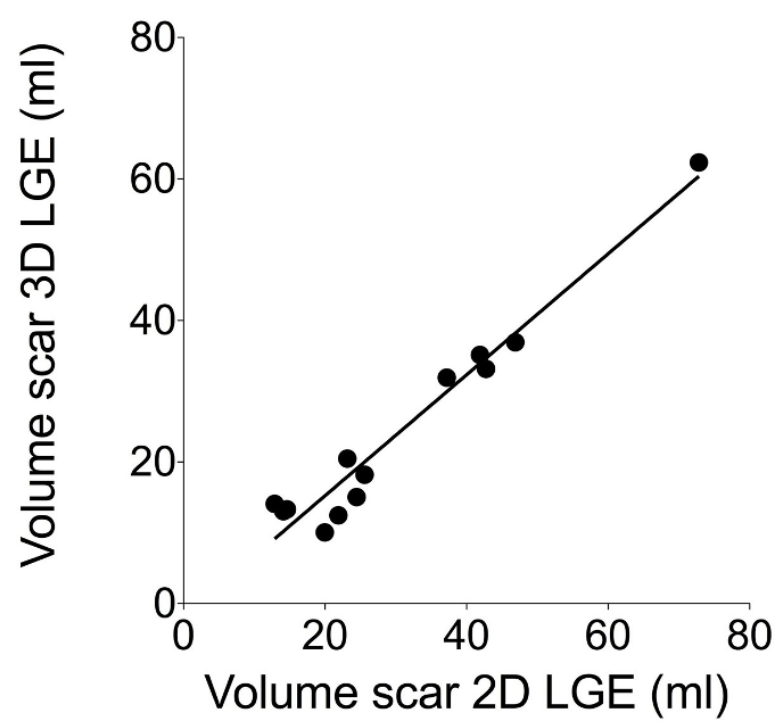

Figure 2 Correlation of volume of scar determined by 2D and 3D late gadolinium enhancement 


\section{Funding}

N/A.

\section{Authors' details}

${ }^{1}$ Center for Biomedical Imaging (CIBM) \& Center for Cardiovascular Magnetic Resonance Research, University of Lausanne, Lausanne, Switzerland. ${ }^{2}$ Division of Cardiology, Cardiac MR Center, University Hospital Lausanne (CHUV),

Lausanne, Switzerland. ${ }^{3}$ Department of Radiology, University Hospital (CHUV) and University of Lausanne (UNIL), Lausanne, Switzerland.

Published: 3 February 2015

doi:10.1186/1532-429X-17-S1-Q121

Cite this article as: Rutz et al: Accuracy of self-navigated free-breathing isotropic 3D whole heart inversion recovery magnetic resonance for detection of myocardial infarction. Journal of Cardiovascular Magnetic

Resonance 2015 17(Suppl 1):Q121.

Submit your next manuscript to BioMed Central and take full advantage of:

- Convenient online submission

- Thorough peer review

- No space constraints or color figure charges

- Immediate publication on acceptance

- Inclusion in PubMed, CAS, Scopus and Google Scholar

- Research which is freely available for redistribution

Submit your manuscript at www.biomedcentral.com/submit 